\title{
The Effect of Single Co-expression of The DnaK-DnaJ-GrpE and GroEL/ES Chaperones and Their Combination on Expression Intein-pretrombin-2 in Escherichia coli ER2566
}

\author{
Iman Permana Maksum ${ }^{1 *}$, D. Agus Yusuf Wildan ${ }^{1}$, Khomaini Hasan², Toto Subroto ${ }^{1}$ \\ ${ }^{1}$ Biomolecular Health and Food Laboratory, Department of Chemistry, Faculty of Mathematics and Natural \\ Sciences, Universitas Padjadjaran, Indonesia, +62227794391 \\ ${ }^{2}$ Medical School, Universitas Jenderal Achmad Yani, Jl. Ters. Jend. Sudirman, Cimahi, 022-6650646 \\ *Corresponding author: iman.permana@unpad.ac.id
}

Received: Mei 2019; Revision: Mei 2019; Accepted: April 2020; Available online: May 2020

\begin{abstract}
The use of recombinant thrombin in the manufacture of fibrin glue allows diseases contamination to be avoided. However, the expression of recombinant protein in $E$. coli still has a disadvantage of the formation of inclusion bodies, so it needs to be minimized by co-expression of chaperones. Therefore, the aim of this study was to determine the effect of single DnaK-DnaJ-GrpE and GroEL/ES chaperone co-expression and their combination on the expression of intein-pretrombin-2Ti,pH on E. coli ER2566. The method started with isolation of pTWIN1-prethrombin- $2_{\mathrm{Ti}, \mathrm{pH}}$ and pG-KJE8 from E. coli TOP10F' and DH5 $\alpha$ respectively, the co-transformation of the expression host $E$. coli ER2566 using pG-KJE8 and pTWIN1-prethrombin-2 ${ }_{\mathrm{Ti}, \mathrm{pH}}$ vectors, the chaperone co-expression was induced using L-Arabinosa before IPTG induction and cell culture growth was incubated at $22{ }^{\circ} \mathrm{C}$. The expression products were characterized by using Sodium dodecyl sulphate-polyacrylamide gel electrophoresis (SDS-PAGE) analysis. The results of the co-expression of chaperone showed that the number of soluble fraction was higher than the one without co-expression of chaperone. In addition, the co-expression of chaperone using pG-KJE8 in intein-prothrombin- $2_{\mathrm{Ti}, \mathrm{pH}}$ expression was sufficient using tetracycline as an inducer.
\end{abstract}

Keywords: Intein-pretrombin- $2_{\mathrm{Ti}, \mathrm{pH}}$, chaperone co-expression of DnaK-DnaJ-GrpE and GroEL/ES, E. coli ER2566

DOI: $10.15408 / j k v \cdot v 6 i 1.11333$

\section{INTRODUCTION}

Autologus fibrin glue (AFG) is an adhesive biomaterial, which consist of thrombin, fibrinogen and factor XIII, that can be applied as substitute to surgical suture (Enus et al., 2006). Providing fibrinogen and Factor XIII from patient themselves are rather quick and simple however, preparation of autologous thrombin takes long time and requires trained personnel. Therefore, recombinant human thrombin were suggested to overcome the problem, while application of recombinant human thrombin in AFG also prevent contamination from infectious disease contaminants.

In this research, recombinant human prethrombin-2 (hPT-2) was expressed as thrombin precursor to AFG component. Expression were conducted under E. coli expression system, using intein as purification tag which later purified using thiol induction (intein-pretrombin- $2_{\mathrm{Ti}}$ ) and $\mathrm{pH}$ induction (intein-pretrombin- $2_{\mathrm{pH}}$ ). This is based on previous research on recombinant thrombin that has been successfully produced in $E$. coli (Soejima et al., 2001). The target protein, hPT2 , was fused with intein tags and chitin binding domain (CBD) that allows purification through affinity column, which is then continued by IMPACT system (Silaban et al., 2014). IMPACT is a purification system developed by New England Biolabs which utilize selfcleavage properties of intein, analogous protein to intron, in its splicing components. The cleavage is induced whether by thiol reagent or pH gradient (Silaban et al., 2016).

Expressing recombinant protein in $E$. coli offers advantages such as rapid growth, simple culture medium, vast strain are available, simple procedure, and relatively 
inexpensive (Maksum et al., 2017a; Maksum et al., 2017b). Although, high expression of heterologous protein often lead to improper protein folding due to inadequate number of chaperone, which may induce formation of insoluble protein aggregate known as inclusion bodies (Choi and Lee, 2004). Recent studies showed that in vivo folding can be assisted by molecular chaperone. Chaperone induce appropriate isomerization of target protein through hydrophobic interaction with protein target (Baneyx, 1999).

Most of prethrombin-2 (PT-2) produced in $E$. coli has minor activity, due to formation of inclusion bodies (Soejima et al., 2001). Therefore, simple strategies to overcome inclusion bodies formation were needed, such as: 1) Intracellular expression with refolding of fusion protein using $E$. coli Artic express (Maksum et al., 2019; S Silaban et al., 2019a; Silaban et al., 2019b) or coexpression using chaperone (Gupta, 2002; Silaban et al., 2014; Rizkia et al., 2015; Silaban et al., 2019c), 2) Extracellular expression using signal peptide and phospholipase co-expression (Sriwidodo et al., 2017; Maksum et al., 2017c; Melati et al., 2019; Indriyani et al., 2019; Indriyani et al., 2020; Latifah et al., 2020) .

Co-expression of chaperone was conducted in this research with the aim to overcome inclusion bodies formation. Chaperone molecules are classified in three functional subclasses based on its mechanism that is, folding chaperone, stabilizing chaperone, and disaggregating chaperone. Folding chaperone (such as GroEL-ES) depends on ATP which promote conformational change to mediate substrate refolding (Baneyx and Mujacic, 2004).

According to Shen et al., 2011, chaperone co-expression also improves the solubility of target protein while also reduce aggregation of recombinant protein lipase LIP948 in E. coli. LIP-948 were efficiently expressed while co-expressed with chaperone combination, GroEL/ES and DnaK-DnaJ-GrpE compared with no co-expression added. This strategy produces $41.8 \%$ soluble fraction from total LIP-948 with respective specific activity $108.77 \mathrm{U} / \mathrm{mg}$, while without co-expression only generate $4.5 \%$ soluble fraction with specific activity of $66.51 \mathrm{U} / \mathrm{mg}$ (Yan et al., 2012).
Other studies (Juozas and Neubauer, 2011) also conduct chaperone co-expression in ribonuclease inhibitor (RI) expression. Coexpression of GroEL/GroES in RI expression showed activity enhancement compared without co-expression (Siurkus, 2013). Both of these studies confirm that chaperone coexpression can improve protein solubility, which later enhance its activity.

Nevertheless, further studies about chaperone-mediated folding are required since each chaperone has different mechanism and its influence in various target protein. Several proteins may have preference to certain chaperone system, LIP-948 were efficiently expressed along with GroEL/ES and DnaKDnaJ-GrpE (from pG-KJE8) co-expression while human basic fibroblast growth factor (hbFGF) expression is best with trigger factor from pTf16 (Alibolandi et al., 2010). Therefore, expression of intein-prethrombin$2_{\mathrm{Ti}, \mathrm{pH}}$ using pG-KJE as chaperone-containing plasmid, will also observe influence of both each chaperone GroEL/ES, DnaK-DnaJ-GrpE and combination of both chaperone.

\section{MATERIALS AND METHODS Materials}

Sample used in this research were $E$. coli TOP10F' [pTWIN1-pretrombin- ${ }_{T i}$, TOP10F' [pTWIN1-pretrombin- $2_{p H}$ ], DH5 $\alpha$ [pG-KJE8], dan untransformed ER2566. Agarose, tris base and glycerol [Genetika Science], bacto agar [Pronadisa], acrylamid [BioRad], aquabidest, ampicillin, APS, acetic acid, comasie brilliant blue R-250 staining solution, EDTA, hydrochloric acid, n-butanol, yeast extract [Titan Biotech LTD], restriction enzyme NdeI, BamHI \& XhoI [NEB], absolute ethanol, ethanol $70 \%$, etidium bromide, glycine dan urea [Merck], IPTG [Thermo Scientific], plasmid isolation kit (High-Speed Plasmid Mini Kit Geneaid $^{T M}$ ), chloramphenicol, calcium chloride, Larabinose, loading dye, DNA marker, protein marker, sodium hydroxide, sodium chloride, SDS [Merck], TEMED, tetracycline, tryptone [Becton].

\section{pTWIN1-pretrombin-2 ${ }_{T i, p H}$ dan pG-KJE8 Plasmid Isolation from Its Respective $E$. coli TOP10F' \\ $5 \mathrm{~mL}$ cell culture were collected into} microtube and centrifuged in $14000 \mathrm{~g}$ for 1 minute to collect cell pellet. Next, $200 \mu \mathrm{L}$ PD1 
buffer with RNase were added and resuspended using vortex machine. Cell then lysed by adding $200 \mu \mathrm{L}$ PD2 buffer and mixed by $10 X$ inversion. Mixture then incubated for 2 minutes before neutralized by $300 \mu \mathrm{L}$ PD3 buffer, then supernatant collected through centrifugation in $14000 \mathrm{~g}$ for 3 minutes. PD column were placed on the collection tube, then added by the supernatant. Later, pellets were collected through centrifugation at 14000 $g$ for 30 seconds. PD column then placed back in the collection tube and centrifuged for 3 minutes with same speed. Next step, $600 \mu \mathrm{L}$ washing buffer containing ethanol were loaded into PD column then centrifuged in $14000 \mathrm{~g}$ for 3 minutes to dry out column matrix. Later, $50 \mu \mathrm{L}$ elution buffer or TE loaded into center of matrix column and allowed to stand for 2 minutes in order to allow absorption. Last, plasmid was collected by centrifugation at $14000 \mathrm{~g}$ for 2 minutes.

\section{E. coli ER2566 Transformation with pG- KJE8 and pTWIN1-pretrombin-2 ${ }_{T i, p H}$ \\ $0.5 \mu \mathrm{L}$ plasmids $\mathrm{pG}$-KJE8 and} pTWIN1-prethrombin- $2_{T i, p H}$ were loaded into microtube containing $50 \mu \mathrm{L}$ competent cell for the chaperone combination method. While for single chaperone method, each $E$. coli were added by $50 \mu \mathrm{L}$ of its respective plasmids before incubation in $4{ }^{\circ} \mathrm{C}$ for 30 minutes. Transformation were conducted through heat shock in $42{ }^{\circ} \mathrm{C}$ for 90 seconds, then rapidly cooled for 10 seconds in ice bath. Mixtures then added by $900 \mu \mathrm{L}$ LB media and incubated with $150 \mathrm{rpm}, 37{ }^{\circ} \mathrm{C}$ for 2 hours. After incubation, culture was centrifuged at $13000 \mathrm{~g}$ for 30 seconds and $850 \mu \mathrm{L}$ supernatant was discarded while the remaining $150 \mu \mathrm{L}$ will be grown in solid LB media, containing $50 \mu \mathrm{g} / \mathrm{mL}$ chloramphenicol dan $100 \mu \mathrm{g} / \mathrm{mL}$ ampicillin. Culture then incubated in $37{ }^{\circ} \mathrm{C}$ for $16-18$ hours. Transformation of E. coli ER2566 by sole pTWIN1-prethrombin- $2_{T i, p H}$ plasmid also conducted as control without chaperone coexpression.

Chaperone Co-expression in E. coli ER2566 [pG-KJE8 + pTWIN1-pretrombin-2 ${ }_{\mathrm{Ti}, \mathrm{pH}}$ ] with Single and Combined Chaperone

Transformants E. coli ER2566[pGKJE8+pTWIN1-prethrombin- $2_{T i, p H}$ ] were grown in $5 \mathrm{~mL}$ liquid $\mathrm{LB}$ containing $50 \mu \mathrm{g} / \mathrm{mL}$ chloramphenicol dan $100 \mu \mathrm{g} / \mathrm{mL}$ ampicillin for 16 hours. Next, $10 \mu \mathrm{L}$ of culture were loaded into Erlenmeyer flask with $50 \mathrm{~mL} \mathrm{LB}$ media with $1 \mathrm{mg} / \mathrm{mL}$ L-arabinose (DnaK-DnaJ-GrpE inducer) and/or $10 \mathrm{ng} / \mathrm{mL}$ tetracycline (GroEL/ES inducer) and antibiotics $(50 \mu \mathrm{g} / \mathrm{mL}$ chloramphenicol dan $100 \mu \mathrm{g} / \mathrm{mL}$ ampicillin) then incubated in $150 \mathrm{rpm}, 37{ }^{\circ} \mathrm{C}$ for 3-4 hours. After incubation, pellet was collected from 1 $\mathrm{mL}$ through centrifugation at $15000 \mathrm{~g}$ for 10 minutes and added by $30 \mu \mathrm{L}$ glycine buffer (as $\mathrm{t}_{0}$ before induction by IPTG). The remaining culture then induced by IPTG with total concentration $75 \mu \mathrm{M}$ in media, and incubated in $22{ }^{\circ} \mathrm{C}$ for 6 hours. Later, pellet was collected from $1 \mathrm{~mL}$ of culture through centrifugation $15000 \mathrm{~g}$ for 10 minutes and added by $60 \mu \mathrm{L}$ glycine buffer (as $t_{1}$ : after IPTG induction). The remaining induced culture then harvested and pellet was collected in microtube using centrifugation at the same speed for 10 minutes. The pellets collected then added by $500 \mu \mathrm{L}$ glycine buffer, sonicated, and centrifuged in $15000 \mathrm{~g}, 4{ }^{\circ} \mathrm{C}$ for 20 minutes. Later supernatant was separated into fresh microtube as soluble fraction or crude extract. While pellet, was added by $50 \mu \mathrm{L} 8 \mathrm{M}$ urea, heated in $95{ }^{\circ} \mathrm{C}$ for 15 minutes, and centrifuged at $15000 \mathrm{~g}$ in $4{ }^{\circ} \mathrm{C}$ for 10 minutes. The supernatant then collected as insoluble fraction.

Tabel 1. Variation of induction treatment on chaperone co-expression in E. coli ER2566 [pG-KJE8 + pTWIN1pretrombin- $\left.2_{\mathrm{Ti}, \mathrm{pH}}\right]$ singly and in combination

\begin{tabular}{cccccc}
\hline & \multicolumn{4}{c}{ Variations in Induction Treatment } \\
\hline \multirow{2}{*}{ Induction type } & \multicolumn{3}{c}{ Chaperone co-expression } & \multirow{2}{*}{$\begin{array}{c}\text { Without chaperone co- } \\
\text { exppression }\end{array}$} \\
\cline { 2 - 4 } & \multicolumn{2}{c}{ Single } & Combination & \\
Tetracycline & $\sqrt{ }$ & - & $\sqrt{ }$ & - \\
L - Arabinose & - & & $\sqrt{ }$ & $\sqrt{ }$ & - \\
\hline
\end{tabular}




\section{Protein Characterization using SDS-PAGE and UV-Vis Spectrophotometer}

The protein expressed was characterized using SDS-PAGE. Gel was prepared by casting resolving gel and stacking gel. Resolving gel was loaded in glass platesheet up to $2 / 3$ volume, then n-butanol was added to help flatten the gel surface and let stands for 30 minutes. After gel hardened, n-butanol was discarded then, stacking gel and comb were loaded and allowed to stand for another 30 minutes. Later, gel was assembled in electrophoresis tank filled with $1 \mathrm{X}$ running buffer. Samples were prepared by mixing 10 $\mu \mathrm{L}$ of each samples with $5 \mu \mathrm{L} 1 \mathrm{X}$ loading dye, then incubated in $95^{\circ} \mathrm{C}$ using water bath for 15 minutes before centrifuged at $15000 \mathrm{~g}$ for 1 minutes. Later, each samples were loaded 20 $\mu \mathrm{L}$ into well and $5 \mu \mathrm{L}$ protein marker was also loaded. Electrophoresis then run at $120 \mathrm{~V}$ for 90-120 minutes. After electrophoresis, gels were stained using coomassie brilliant blue R250 staining solution for 5 hours and destained for 2 hours, then rinsed in aquadest before dried and analyzed.

Protein wavelength absorption from 2 expression system (pTWIN1-prethrombin- $2_{T i}$ dan pTWIN1-prethrombin-2 ${ }_{p H}$ ) with/without chaperone co-expression (both single or combination method) were measured at $\lambda 280$ $\mathrm{nm}$ using UV-vis spectrophotometer [Ultrospec 3000 Pro].

\section{RESULTS AND DISCUSSION Without Chaperone Co-expression}

Ekspression of ER2566 [pTWIN1prethrombin- $\left.2_{T, p H}\right]$ without chaperone coexpression were conducted as control comparison. Protein expression induced by IPTG with total concentration $75 \mu \mathrm{M}$ and incubated in $22{ }^{\circ} \mathrm{C}$ for 6 hours. The results were shown in Fig. 1A, prethrombin- $2_{\mathrm{Ti}, \mathrm{pH}}$ fused with intein gives protein band in $63 \mathrm{kDa}$ which appeared in insoluble fraction. High-rate expression and inadequate folding are reasons of this result. Therefore, chaperone coexpression was conducted to resolve this problem.

Intein-prethrombin-2 ${ }_{\mathrm{Ti}, \mathrm{pH}}$ Expression with Combined GroEL/ES + DnaK-DnaJ-GrpE Chaperone Co-expression

Both chaperones inducer, L-arabinose and tetracycline for DnaK-DnaJ-GrpE and GroEL/ES respectively, were added into media before transformant was first cultured in $37{ }^{\circ} \mathrm{C}$ at $150 \mathrm{rpm}$. While cultured grown, both chaperones will be expressed first since both were induced first. This corresponds to Table 1 , which both chaperone absorption was greater with prethrombine as a result of early chaperone induction compared to protein target. Early chaperone induction allowed cells to provide chaperones, so when protein target expression was induced chaperones were ready to help protein folding. It is shown that inteinprethrombin- $2_{\mathrm{Ti}, \mathrm{pH}}$ expression under GroEL/ES co-expression has better protein yield in soluble fraction compared to DnaK-DnaJGrpE solely and in combination of chaperones (Figure 1). This is caused by GroEL role which help protein folding by providing folding space, so that intein-prethrombin- $2_{\mathrm{Ti}, \mathrm{pH}}$ folding undergoes without surrounding disturbance. It is shown that co-expression induced by Larabinose has less soluble fraction, it is likely when DnaK-DnaJ-GrpE is combined with GroEL/ES, it will reduce the soluble protein from intein-prethrombin- $2_{\mathrm{Ti}, \mathrm{pH}}$ due to competition for binding of protein substrates (intein-prethrombin- $2_{\mathrm{Ti}, \mathrm{pH}}$ ) between GroEL and DnaK, which when intein-prethrombin- $2_{\mathrm{Ti}, \mathrm{pH}}$ expressed with DnaK is no better than when expressed with GroEL. Apart from that, tetracycline seems has optimum effect than Larabinose, since host and its vector do not contain any tetracycllin-resistant gene.

Result of combined chaperone coexpression shown in Fig 1B, exhibit inteinprethrombin- $2_{\mathrm{Ti}, \mathrm{pH}}$ band in soluble fraction. This indicate that chaperones assist inteinprethrombin- $2_{\mathrm{Ti}, \mathrm{pH}}$ folding which may result to improving soluble fraction of target protein. Furthermore, availability of folding space provided by GroEL allowed efficient folding of intein-prethrombin- $2_{\mathrm{Ti}, \mathrm{pH}}$, although insoluble fraction also exhibit notable inteinprethrombin- $2_{\mathrm{Ti}, \mathrm{pH}}$ band.

\section{Single DnaK-DnaJ-GrpE Chaperone Co- expression in Intein-prethrombin- $2_{\mathrm{Ti}, \mathrm{pH}}$ Expression \\ DnaK-DnaJ-GrpE was expressed after} L-arabinose induction. Figure $1 \mathrm{C}$ exhibit intein-pretrombin- $2_{\mathrm{Ti}, \mathrm{pH}}$ band, yet it has lower band thickness compared to Fig 1A. The reduction of soluble fraction from DnaK-DnaJGrpE co-expression might be caused by absence of folding space as well as provided in 
GroEL system, this may have allowed environmental disturbance to disturb folding. It is also caused by Hsp70 including DnaK, which help folding and degradation of unstable protein (Henderson and Pockley, 2010), execute intein-pretrombin- $2_{\mathrm{Ti}, \mathrm{pH}}$ degradation due to protein crowd which occupy limited space of cytoplasm, to prevent stability disturbance of surrounding proteins. Other possibility, L-arabinose used as inducer may have been metabolized by cells as carbon source so it does not utilize as inducer optimally (Yan et al., 2012). Furthermore, there were no mutation found on $E$. coli ER2566 which may disrupt L-arabinose metabolism. While this problem has already countermeasured by increasing L-arabinose concentration, it appears that optimization of L-arabinose concentration still need to be studied to achieve high-yield protein target.

\section{Single GroEL/ES Chaperone co-expression in intein-prethrombin-2 ${ }_{\mathrm{Ti}, \mathrm{pH}}$ expression}

GroEL/ES were expressed after tetracycline induction. Fig. 1D shows that intein-prethrombin- $2_{\mathrm{Ti}, \mathrm{pH}}$ in soluble fraction has more protein than soluble fraction from sole DnaK-DnaJ-GrpE and combined chaperones system. It is strongly estimated caused by folding space provided by GroEL which help folding and reduce environmental disturbance. As discussed in previous section, coexpression induced by L-arabinose yields lower soluble fraction of intein-prethrombin-
$2_{\mathrm{Ti}, \mathrm{pH}}$, which may correspond to reduced yield in DnaK-DnaJ-GrpE + GroEL/ES combination system. It is also due to GroEL and DnaK binding competition for protein substrate that gives no better result as previously described. While tetracycline also may play role as it might have optimal role as inducer solely compared to L-arabinose, due to absence of tetracycline-resistant gene.

Although chaperone help inteinprethrombin- $2_{\mathrm{Ti}, \mathrm{pH}}$ folding which lead to increasing its soluble fraction, but total protein produced using chaperone co-expression was decreased. This was measured using spectrophotometer at $280 \mathrm{~nm}$ from respective soluble fraction samples, as shown in Table 2. It is appropriate that co-expression of chaperons can inhibit the growth of E. coli and reduce the level of expressed proteins (Garciacarbonero et al., 2013). Competition between inducers seem to play a role since they were in same system, whether IPTG, L-arabinose, and tetracycline, thus interfere each induction process and resulting in lower protein production. However, chaperone co-expression using pG-KJE8 induced by tetracycline exhibit highest value among other chaperone coexpression system. Although without chaperone co-expression, especially [ER2566+pTWIN1-pretrombin-2 $2_{T i}$, exhibit greater absorbance, it has no inteinprethrombin- $2_{\mathrm{Ti}}$ appeared in soluble fraction as shown in Fig. 1A.
A

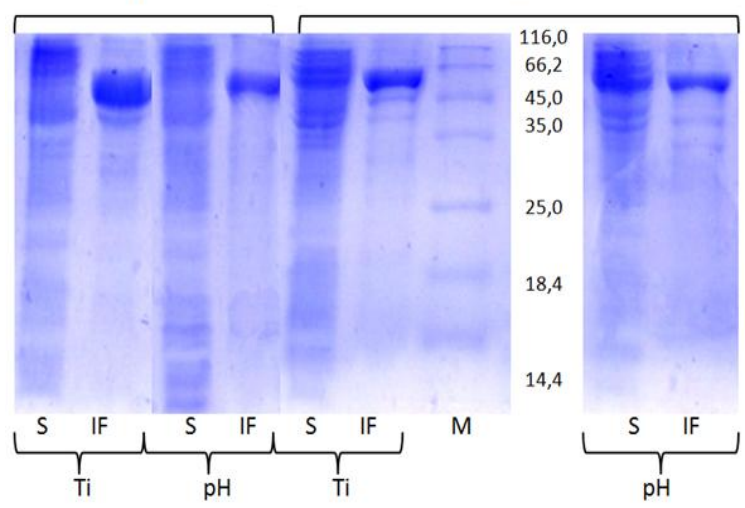

C

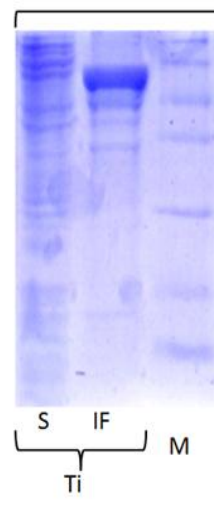

D

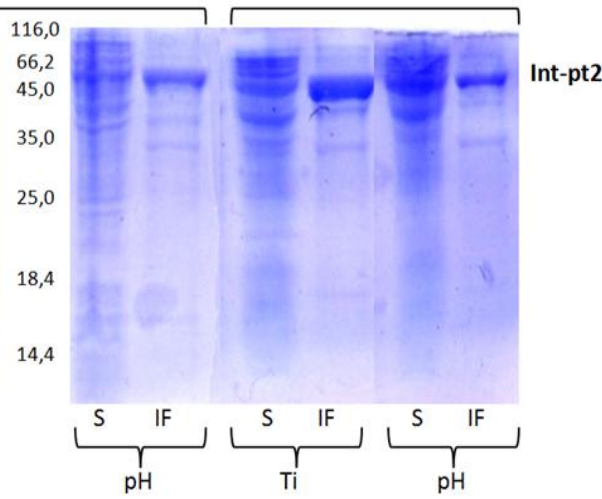

Figure 1. SDS-PAGE Electrophoregram of intein-pretrombin- $2_{\mathrm{Ti}, \mathrm{pH}}$ expression with and without chaperone coexpression. A) without co-expression; B) GroEL/ES + DnaK-DnaJ-GrpE co-expression; C) DnaK-DnaJ-GrpE co-expression; and D) GroEL/ES co-expression. M, marker protein; S, soluble; IF, insoluble fraction; Ti, pTWIN1-prethrombin- $2_{T i}$; pH, pTWIN1-prethrombin- $2_{p H}$; int-pt2 : intein-prethrombin- $2_{\mathrm{Ti}, \mathrm{pH}}$. Expression were conducted in $37{ }^{\circ} \mathrm{C}$ for 3 hours (before induction) and $22{ }^{\circ} \mathrm{C}$ for 6 hours (after induction). 
Table 2. Soluble Fraction absorbance at $\lambda 280 \mathrm{~nm}$ from two expression systems. (pTWIN1-prethrombin- $2_{T i}$; pTWIN1-prethrombin- ${ }_{p H}$ )

\begin{tabular}{|c|c|c|}
\hline \multirow{2}{*}{ Expression System } & \multicolumn{2}{|c|}{ Absorbance } \\
\hline & $\mathbf{T i}$ & pH \\
\hline E. coli ER2566 & 0.757 & 0.551 \\
\hline $\begin{array}{l}\text { E. coli } \mathrm{ER} 2566+\text { pG-KJE8 combined chaperones } \\
\text { (induced by L-arabinose and tetracycline) }\end{array}$ & 0.467 & 0.420 \\
\hline $\begin{array}{l}\text { E. coli ER } 2566+\text { pG-KJE8 single chaperone } \\
\text { (induced by L-arabinose) }\end{array}$ & 0.491 & 0.488 \\
\hline $\begin{array}{l}\text { E. coli ER } 2566+\text { pG-KJE8 single chaperone } \\
\text { (induced by tetracycline) }\end{array}$ & 0.720 & 0.639 \\
\hline
\end{tabular}

Note: Ti: pretrombin- $2_{\mathrm{Ti}}$ absorbance; $\mathrm{pH}$ : pretrombin- $2_{\mathrm{pH}}$ absorbance

In addition, since SDS-PAGE only give qualitative and semi-quantitative profile about protein of interest, it is better to comprehend SDS-PAGE data and have more precise result to help analysis. SDS-PAGE data may have come to bias in distinction our protein target with other protein that has similar molecular weight, in example, GroEL molecular weight were $57 \mathrm{kDa}$ which close to our protein target $63 \mathrm{kDa}$ and may give overlapping band. Therefore, to determine and assure our protein target, western blot analysis will be helpful while, accurate measurement of prethrombin-2 level requires further purification steps. However, one unique characteristic of expression using the T7 RNA polymerase regulated by the $\mathrm{T} 7$ promoter in the pTWIN1 vector is its high level of expression, and shows the thickest protein band among the others.

\section{CONCLUSSION}

From the results of the research that has been done, it can be concluded that according to SDS-PAGE analysis and absorption analysis at $\lambda 280 \mathrm{~nm}$, chaperone coexpression of the GroEL/ES, DnaK-DnaJGrpE, and a combination of GroEL/ES and DnaK-DnaJ-GrpE in the expression of inteinpretrombin- $2_{\mathrm{Ti}, \mathrm{pH}}$, in E. coli ER2566 shows an increase in the soluble fraction compared without co-expression, especially when coexpressed with GroEL/ES solely.

\section{ACKNOWLEDGEMENT}

The author thanks the Director General of the Directorate General of Higher Education Ministry of Research and Technology of Higher Education, the chairman, chair of the Research Institute, Dean of the Faculty of Mathematics and Natural Sciences, Chair of the Department and all staff of the Center for Molecular Biology and Bioinformatics Research at Padjajaran University who have assisted in conducting this research.

\section{REFFERENCES}

Alibolandi M, Mirzahoseini H, Nehi FM, Tabatabaian G. 2010. Improving recombinant protein solubility in Escherichia coli : Identification of best chaperone combination which assists folding of human basic fibroblast growth factor. African Journal of Biotechnology. 9(47): 8100-8109.

Baneyx F. 1999. Recombinant protein expression in Escherichia coli. Current opinion in biotechnology. 10(5): 411-421.

Baneyx F, Mujacic M. 2004. Recombinant protein folding and misfolding in Escherichia coli. Nature Biotechnology. 22(11): 1399-1407.

Choi JH, Lee SY. 2004. Secretory and extracellular production of recombinant proteins using Escherichia coli. Applied Microbiology and Biotechnology. 64(5): 625-635.

Enus S, Dalimoenthe NZ, Kartiwa A. 2006. Teknik lem fibrin otologus pada cangkok konjungtiva bulbi mata kelinci bulbar conjunctival graft using an autologous fibrin glue in rabbit eyes. Majalah Kedokteran Bandung. 41(4): 169-173.

Garcia-carbonero R, Carnero A, Paz-ares L. 2013. Inhibition of HSP90 molecular chaperones: moving into. Lancet Oncology. 14(9): e358-e369.

Gupta SRVKA. 2002. Role of the general stress response during strong overexpression of a heterologous gene in Escherichia coli. 
Applied Microbiology and Biotechnology. 58(3): 330-337.

Henderson B, Pockley AG. 2010. Molecular chaperones and protein-folding catalysts as intercellular signaling regulators in immunity and inflammation. Journal of Leukocyte Biology. 88(3): 445-462.

Indriyani A, Anggraeni NI, Sriwidodo, Maksum IP. 2019. Optimization extracellular secretion of recombinant human epidermal growth factor (hEGF) in Escherichia coli BL21 (DE3) pd881-ompa-hegf by using response surface method (RSM). International Journal of Research in Pharmaceutical Sciences. 10(3): 18241831.

Indriyani A, Gaffar S, Latifah FPU, Maksum IP. 2020. Co-expression of recombinant human epidermal growth factor (rhEGF) In Escherichia coli BL21 (DE3) with Bacillus cereus phospholipase C. In AIP Proceeding.

Juozas Š, Neubauer P. 2011. Heterologous production of active ribonuclease inhibitor in Escherichia coli by redox state control and chaperonin coexpression. Microbial Cell Factories. 10(1): 1-11.

Latifah FPU, Indriyani A, Pratiwi R, Sriwidodo, Maksum IP. 2020. Effects of growth medium on extracellular secretion of human epidermal growth factor in Escherichia coli by co-expression with Bacillus cereus Phospholipase C. In IOP Conference Series.

Maksum IP, Sriwidodo S, Yosua Y. 2019. Strategi Peningkatan Ekspresi Protein Rekombinan Secara Intraselular pada Inang. Sumedang: Alqaprint.

Maksum IP, Utama E, Sriwidodo S, Subroto T. 2017. Extracellular secretion of recombinant human epidermal growth factor by using trimethylamine N-Oxide reductase a (TORA) signal peptide in escherichia coli BL21 (DE3). Journal of Pharmaceutical Sciences and Research. 9(6): 1007-1016.

Maksum IP, Sriwidodo, Gaffar S, Hasan K, Subroto T, Soemitro S. 2017. Teknik Biologi Molekular. Sumedang: Alqaprint.

Maksum IP, Sriwidodo, Indriyani A. 2017. Sistem Ekspresi Protein Rekombinan dalam
Escherichia coli secara Ekstraselular. Sumedang: Alqaprint.

Melati R, Indriyani A, Gaffar S, Sriwidodo S, Maksum IP. 2019. Comparison of extracelullar secretion of recombinant human epidermal growth factor using TorA and PelB signal peptides in Escherichia coli BL21 (DE3). Asian Journal of Pharmaceutical and Clinical Research. 12(11): 81-84.

Rizkia PR, Silaban S, Hasan K, Kamara DS, Subroto T, Soemitro S, Maksum IP. 2015. Effect of isopropyl- $\beta$-Dthiogalactopyranoside concentration on prethrombin-2 recombinan gene expression in Escherichia coli ER2566. Procedia Chemistry. 17(2015): 118-124.

Silaban S, Gaffar S, Simorangkir M, Maksum IP, Subroto T. 2019a. Construction and optimization of prethrombin-2 human genes in e. coli for the production of active thrombin. Journal of Physics: Conference Series. 1374: 12047.

Silaban S, Gaffar S, Simorangkir M, Maksum IP, Subroto T. 2019b. Effect of IPTG concentration on recombinant human prethrombin-2 expression in escherichia coli BL21(DE3) arctic express. IOP Conference Series: Earth and Environmental Science. 217: 12039.

Silaban S, Maksum IP, Enus S. 2016. Kajian ekspresi gen pretrombin-2 manusia sintetik pada Escherichia coli secara in silico untuk produksi trombin. Jurnal Pendidikan Kimia. 8(1): 58-64.

Silaban S, Maksum IP, Ghaffar S, Hasan K, Enus S, Subroto T. 2014. Codon optimization and chaperone assisted solubilization of recombinant human prethrombin-2 expressed in Escherichia coli. Microbiology Indonesia. 8(4): 170-175.

Silaban, Saronom, Simorangkir M, Gaffar S, Maksum I, Subroto T. 2019. Temperature effect on expression of recombinant human prethrombin-2 in Escherichia coli BL21(DE3) Arctic Express. Jurnal Pendidikan Kimia. 11(3): 122-128.

Siurkus J. 2013. Approach for production of sensitive to oxidation and aggregating proteins in E. coli at the example of a heterologous ribonuclease inhibitor. 
Soejima K, Mimura N, Yonemura H, Nakatake H, Imamura T, Nozaki C. 2001. An efficient refolding method for the preparation of recombinant human prethrombin-2 and characterization of the recombinantderived alpha thrombin. Journal of Biochemistry. 130(2): 269-277.

Sriwidodo S, Maksum IP, Riswanto N, Rostinawati T, Subroto T. 2017. Extracellular secretion recombinant of human epidermal growth factor (hEGF) using pectate lyase B (PelB) signal peptide in Escherichia coli
BL21(DE3). International Journal of Research in Pharmaceutical Sciences. 8(1): 33-40.

Yan X, Hu S, Guan YX, Yao SJ. 2012. Coexpression of chaperonin GroEL/GroES markedly enhanced soluble and functional expression of recombinant human interferon-gamma in Escherichia coli. Applied Microbiology and Biotechnology. 93(3): 1065-1074. 